\title{
Discriminating Bangladeshi Adults by Level of Blood Pressure
}

\author{
Bhuyan KC* \\ Department of Statistics, Jahangirnagar University, Dhaka, Bangladesh
}

*Correspondence: KC Bhuyan, Department of Statistics, Jahangirnagar University, Dhaka, Bangladesh

Received on 07 September 2020; Accepted on 26 October 2020; Published on 26 November 2020

Copyright () 2020 Bhuyan KC. This is an open access article and is distributed under the Creative Commons Attribution License, which permits unrestricted use, distribution, and reproduction in any medium, provided the original work is properly cited.

\begin{abstract}
The objective of the present work was to discriminate Bangladeshi adults of 18 years and above according to their blood pressure level and to identify some factors responsible for discrimination. Accordingly, the analysis was done utilizing the data collected from 960 adults of both urban and rural areas. The respondents were investigated by some doctors and nurses from and nearby their working places. During investigation, the blood pressure ( $\mathrm{mmHg}$ ) of the respondents were recorded. It was observed that $45.4 \%$ adults had optimal blood pressure. The percentages of normal, high normal and hypertensive adults were 39.5, 9.4 and 5.7, respectively. High normal and hypertension was more likely among urban, non-Muslim, female, single, aged, illiterate, physically inactive, involved in sedentary activities, obese subjects. Adults of lower income group of families and higher expenditure group of families were also more exposed to the problem of higher blood pressure. The problem was more likely in smokers, restaurant and can food consumers. Age, utilization of time, and accustomed with can food were the most responsible factors in discriminating the adults of different groups. The other responsible variables were gender variation, level of education and body mass index (BMI).
\end{abstract}

Keywords: levels of blood pressure, socioeconomic variables, association, risk ratio, confidence interval of risk ratio, discriminant analysis

Abbreviations: BMI: body mass index; RR: risk ratio; CI: confidence interval

\section{Introduction}

Elevated blood pressure, sometimes termed hypertension, can lead to severe health complications worldwide [1, 2]. It increases the risk of heart disease, stroke, and sometimes death [3-7]. The problem is recognized as modifiable risk factor for cardiovascular disease and at an end stage renal disease [1]. But it is the major cause of premature death worldwide [4]. Number of adults with hypertension increased from 594 million in 1975 to 1.13 billion in 2015. The increase was noted largely in low-and-middle-income countries. Around 7.5 million deaths or $12.8 \%$ of the total of 
all deaths worldwide occur due to high blood pressure [8]. It is predicted to be increased to 1.56 billion adults with hypertension in 2025 [9]. The risk factor of hypertension is cardiovascular and its related diseases and aneurysm. The causes of hypertension are diabetes, kidney diseases, nerve damage, overactive thyroid gland, sleep apnea, pregnancy, and obesity, etc. [5, 6, 10-12]. The prevalence rate was $28.6 \%$ among adults of age 18 years and above [12]. Prevalence rate was increased greatly with age, ranging from $6.8 \%$ among individuals aged $18-39$ years, to $30.4 \%$ in subjects aged 40-59 years and to $66.7 \%$ among adults aged 60 years and above [12]. The associated factors for this health hazard are residence, age, ethnicity, sex, sedentary lifestyle, consumption of alcohol, tobacco smoking, intake of salt rich food and high fat food, physical inactivity, and obesity, etc. [1, 2, 5, 13-17].

The findings mentioned above were noted in hypertensive adults. Predictors for Bangladeshi adults were also mentioned [15]. For pre-hypertensive adults no predictors were identified separately. The noted predictors may or may not be true for pre-hypertensive group of individuals. Because lifestyle factors are key interventional targets in primordial prevention of cardiovascular disease [18]. It was reported that eldest age group was a risk factor for hypertension [5]. But regular physical activity and diet control can reduce the blood pressure and body weight [18]. Moreover, some socioeconomic variables or a particular level of a variable may not enhance the blood pressure of all types of subjects. In almost all studies mentioned above, physical inactivity and obesity were identified as the risk factors for hypertension. But all obese and hypertensive adults of different ages were not physically inactive. This is an opposite picture, statistically true or not, and is not reported. The present analysis was aimed to observe the behaviour of different levels of socioeconomic variables on different levels of blood pressure and to identify some responsible factors for the variation in different blood pressure levels.

\section{Methodology}

The data for this analysis were recorded from urban and rural adults of ages 18 years and above by quota sampling plan to cover $70 \%$ diabetic patients [19] so that sufficient number of adults suffering from different diseases related to diabetes and obesity would be included in the sample. During investigation, data were recorded from 960 subjects consisting of $66.9 \%$ diabetic and $33.1 \%$ non-diabetic subjects. These subjects were investigated by some doctors and nurses from and nearby their working places during the academic session 2017-2018 by direct interview. Data were recorded from respondents through a pre-designed and pre-tested questionnaire. Maximum questions in the questionnaire were related to different socioeconomic variables of the respondents and of the families. Except 3 information, viz. monthly family income, monthly family expenditure and occupation of respondents, all other questions were related to different socio-demographic variables of the respondents and of their lifestyle, specifically their personal food habit, working habit, physical activity, utilization of time, etc. For diabetic patients there were questions related to duration of disease, disease related health hazard, i.e., eye problem, kidney problem, heart problem, blood pressure, blood sugar, treatment stage of disease, admission into hospital, etc. The value of each of the variable was noted in nominal scale. The data of weight $(\mathrm{kg})$ divided by height $\left(\mathrm{m}^{2}\right)$ was used to measure the value of body mass index (BMI). The investigated subjects were classified into 4 classes, viz. underweight (if BMI $<20$ ), normal $(20<\mathrm{BMI}<25)$, overweight $(25<\mathrm{BMI}<30)$ and obese $(\mathrm{BMI} \geq 30)$. They were also divided into 4 groups according to their blood pressure (BP) level (mmHg). The 4 groups were identified as optimal (BP < 120/80), normal (BP < 130/85), high normal (BP < 140/90) and hypertensive $(\mathrm{BP} \geq 140 / 90)$ [20].

According to the objective of the study, association of any of the socioeconomic characteristics with level of blood pressure was examined. Significant association was decided if probability of any chi-square test statistic used for observing association $\leq 0.05$. Irrespective of significant or insignificant association, the risk ratio $[R R]$ in favour of a higher group (\%) of high normal and hypertensive adults compared to two other groups along with $95 \%$ confidence interval (CI) of RR was calculated. The RR was also calculated separately for the first two groups of adults to observe the risk factors for normal group and for the last two groups to observe the risk of hypertensive adults compared to high normal group. The RR was also calculated for high normal group compared to first two groups. Finally, discriminant analysis [21-23] was done to discriminate the 4 groups of subjects and to identify the important variables for this discrimination. Statistical calculation was done using SPSS version 25. 


\section{Results}

In the sample, $45.4 \%$ were of optimal blood pressure. The percentages of adults of normal, high normal and hypertensive were 39.5, 9.4 and 5.7, respectively. These percentages among rural adults (43.5\%) were 43.1, 40.4, 9.6, and 6.9, respectively. The corresponding percentages among urban adults $(56.5 \%)$ were not significantly different from those of rural adults $\left[\chi^{2}=2.991, \mathrm{p}\right.$ value $\left.=0.393\right]$. Insignificant differences in rural and urban adults having optimal and normal blood pressure was noted $\left[\chi^{2}=0.91\right.$, p value $\left.>0.05\right]$. Similar insignificant differences were also observed for high and hypertensive blood pressure $\left[\chi^{2}=0.94\right.$, $p$ value $\left.>0.05\right]$. But higher blood pressure level was 1.18 times likely in rural adults as in urban adults $[\mathrm{RR}=1.18$; $\mathrm{CI}(0.874,1.593)]$. For rural adults, high blood pressure was not a risk factor compared to optimal and normal blood pressure [RR $=1.06]$. The percentage of non-Muslim adults was only 17.4 and $16.2 \%$ of them had high normal and high and hypertensive blood pressure. The corresponding percentage among Muslim subjects was 14.9. However, both the religious groups were at similar risk of higher blood pressure $[\mathrm{RR}=1.09, \mathrm{CI}(0.742,1.601)]$. Blood pressure level was significantly different for the religious groups $\left[\chi^{2}=\right.$ 14.131, $\mathrm{p}$ value $=0.001]$. This significant difference might be attributable due to the difference in the proportions of adults of optimal and normal groups. It was noted by chi-square test, where $\chi^{2}=18.51, \mathrm{p}$ value $=0.00$. Muslim and non-Muslim adults of high blood pressure had the similar risk compared to the risk of adults of optimal and normal blood pressure $[R R=1.03]$. Proportions of Muslim and non-Muslim respondents of optimal and normal blood pressure were significantly different $\left[\chi^{2}=18.51, \mathrm{p}\right.$ value $\left.=0.00\right]$. Optimal blood pressure was 1.40 times likely in non-Muslims as in Muslims [RR $=1.40]$. Male (55.2\%) and female (44.8\%) adults were almost at similar risk of high blood pressure compared to optimal and normal groups $[\mathrm{RR}=1.13, \mathrm{CI}(0.834,1.531)]$. Among optimal and normal groups also males and females were at similar risk $[\mathrm{RR}=0.83]$. But the proportions of male and female adults of all blood pressure levels were significantly different $\left[\chi^{2}=15.493\right.$, $\mathrm{p}$ value $\left.=0.001\right]$. Significant differences were also observed in males and females having optimal and normal blood pressure $\left[\chi^{2}=7.64, \mathrm{p}\right.$ value $\left.<0.01\right]$ and having high normal and hypertensive blood pressure $\left[\chi^{2}=7.43, \mathrm{p}\right.$ value $\left.<0.01\right]$. Similar significant differences in the proportions of blood pressure levels of married and single adults were also noted $\left[\chi^{2}=50.792\right.$, $p$ value $\left.=0.000\right]$. Higher blood pressure was 1.97 times likely in married persons as in single persons $[R R=1.97$, CI $(1.360,2.853)]$. On the other hand, normal blood pressure was 0.65 times likely in married adults as in single adults [ $R R=0.65]$. However, married and single adults having optimal and normal blood pressure were significantly different $\left[\chi^{2}=44.09, \mathrm{p}\right.$ value $\left.=0.000\right]$. But insignificant differences were observed in high and hypertensive group of adults $\left[\chi^{2}=0.22\right.$, $p$ value $\left.>0.05\right]$. Again, high normal blood pressure was 1.46 times likely in married adults as in single adults of lower blood pressure $[\mathrm{RR}=$ 1.46]. The variable age was significantly associated with level of blood pressure $\left[\chi^{2}=152.974, p\right.$ value $\left.=0.000\right]$ and eldest adults ( 40 years and above, $34.2 \%$ ) were 2.01 times likely to be affected by higher blood pressure level $[\mathrm{RR}=$ 2.01 , CI $(1.440,2.805)]$. Adults of ages 40 years and above having higher and hypertensive blood pressure were significantly different from other adults $\left[\chi^{2}=8.52\right.$, $\mathrm{p}$ value $\left.<0.01\right]$. Eldest adults of normal blood pressure were 2.07 times likely to be affected compared to subjects of other ages of optimal blood pressure [RR $=2.07]$. Again, high normal blood pressure was 2.29 times likely in eldest group as in other groups [ $R R=2.29]$. Most of the adults $(58.5 \%)$ were higher educated and higher blood pressure was prevailed among $15.8 \%$ of them. Illiterate adults were only $5.6 \%$, but $20.4 \%$ of them had higher blood pressure. With the increase in level of education there was a decreasing trend in the proportion of adults having higher blood pressure. However, level of education was not significantly associated with level of blood pressure $\left[\chi^{2}=16.064, \mathrm{p}\right.$ value $\left.=0.064\right]$. But illiterate subjects had $38 \%$ more risk of facing the problem of higher blood pressure compared to that of other subjects [RR $=1.38, \mathrm{CI}(0.691,2.756]$. This group of adults of optimal and normal blood pressure had similar risk of the problem $[R R=1.00]$. Illiterate adults of high normal blood pressure also had almost similar risk $[R R=0.93]$. In the sample there were $9.6 \%$ obese adults and $26.1 \%$ of them had higher blood pressure. The corresponding percentages among underweight $(9.5 \%)$, normal (13.6\%) and overweight $(15.6 \%)$ were lower. These differences in proportions were significant $\left[\chi^{2}=50.45, \mathrm{p}\right.$ value $\left.=0.000\right]$. The level of obesity and level of blood pressure was significantly associated $\left[\chi^{2}=22.642\right.$, $\mathrm{p}$ value $\left.=0.007\right]$. Higher blood pressure was 1.87 times likely among obese adults as in other subjects $[R R=1.87, \mathrm{CI}(1.276,2.740)]$. The risk for obese adults having optimal and normal blood pressure was almost same $[R R=0.96]$. But this risk for obese adults 
of normal blood pressure was more as in adults of lower blood pressure [RR $=1.33]$. Prevalence of diabetes was significantly associated with level of blood pressure $\left[\chi^{2}=146.954, \mathrm{p}\right.$ value $\left.=0.000\right]$. But non-diabetic adults were at higher risk of higher blood pressure $[R R=2.94$, CI $(2.170,3.984)]$. But, non-diabetic subjects of normal blood pressure had almost similar risk $[R R=1.15]$ of the problem.

Housewives and others were majority (34.5\%) in the sample and $18.8 \%$ of them had higher blood pressure. Next bigger group (14.3\%) with higher blood pressure was noted among businesspersons and skilled workers. They were $16.8 \%$ in the sample. Here occupation and level of blood sugar were significantly associated $\left[\chi^{2}=20.198, \mathrm{p}\right.$ value $=$ 0.017]. Higher blood pressure was 1.42 times likely in housewives and others as in subjects of other occupational groups $[\mathrm{RR}=1.42$, CI $(1.052,1.917]$. The risk for housewives of optimal groups was almost similar as in normal groups $[R R=1.08]$. There was no significant difference in the proportion of housewives and others and in the proportion of other occupational groups who had optimal and normal blood pressure $\left[\chi^{2}=1.12, p\right.$ value $\left.>0.05\right]$. But high normal blood pressure was 1.26 times likely in housewives as in other occupation groups [RR $=1.26]$. Majority (32.4\%) respondents were from lower income families and $16.4 \%$ of them had higher blood pressure. There was no definite trend in proportion of higher blood pressure group of adults with the change in upward family income level. The chi-square test also did not signify any association between family income and level of blood pressure $\left[\chi^{2}=\right.$ 14.409 , $\mathrm{p}$ value $=0.275]$. However, adults from lower income families had only $13 \%$ more risk of facing the problem of higher blood pressure $[\mathrm{RR}=1.13, \mathrm{CI}(0.826,1.546)]$. Similar was the case with adults who belonged to families of lower expenditure group. They had $18 \%$ more risk to be affected by the problem [RR $=1.18$, CI $(0.874,1.593)]$. Family expenditure was not statistically associated with level of blood pressure $\left[\chi^{2}=17.634, p\right.$ value $\left.=0.127\right]$.

Out of 145 adults of higher blood pressure 85 were involved in sedentary activities and due to this activity higher blood pressure was 2.67 times likely in them as in others $[\mathrm{RR}=2.67, \mathrm{CI}(1.974,3.611)]$. The utilization of time by the adults was significantly associated with level of blood pressure $\left[\chi^{2}=240.425\right.$, $p$ value $\left.=0.000\right]$. High normal blood pressure was 3.46 times likely among adults involved in sedentary activities as in others [ $R R=3.46]$. Another group of adults were not doing any physical work. Their percentage was 63.4 and $17.1 \%$ of them had higher blood pressure. This problem was 1.46 times likely in them as in others $[\mathrm{RR}=1.46, \mathrm{CI}(1.044,2.041)]$. However, physical labour was independent of level of blood pressure $\left[\chi^{2}=6.172\right.$, $p$ value $\left.=0.104\right]$. Non-involvement in physical work was not a risk factor for adults of normal blood pressure in comparison with adults of optimal blood pressure [RR $=1.08]$. But high normal blood pressure was 2.06 times likely in physically inactive adults as in others [RR $=2.06]$. Habit of taking restaurant food was noted among $51.4 \%$ adults and $16.0 \%$ of them had higher blood pressure. Significant association between habit of taking restaurant food and level of blood pressure was observed $\left[\chi^{2}=13.826, p\right.$ value $\left.=0.003\right]$. The restaurant food consumers were at $13 \%$ more risk of higher blood pressure $[\mathrm{RR}=1.13, \mathrm{CI}(0.836,1.528)]$. Habit of taking restaurant food was similar for adults of optimal and normal blood pressure $\left[\chi^{2}=3.58\right.$, $p$ value $\left.=0.065\right]$. These two groups were at similar risk of the problem $[R R=1.10]$. The risk was also almost similar for adults of high normal blood pressure [RR $=0.95]$. The percentage of can food users was 60.8 and $18.1 \%$ of them had high blood pressure as against $10.1 \%$ of the same group in the sample. High blood pressure was 1.75 times likely in can food users as in non-user adults $[\mathrm{RR}=1.75$, CI $(1.242,2.466)]$. Blood pressure levels were significantly different among can food users $\left[\chi^{2}=30.399\right.$, $\mathrm{p}$ value $\left.=0.000\right]$. The respondents of can food users having normal blood pressure had $31 \%$ more risk compared to that of adults having lower blood pressure $[\mathrm{RR}=1.31]$. The percentage of smokers was 38.9 and $16.3 \%$ of them were patients of higher blood pressure. They had $31 \%$ more risk of this health hazard [RR $=1.31, \mathrm{CI}$ $(0.971,1.768)]$. The proportions of smokers of different level of blood pressure were significantly different $\left[\chi^{2}=\right.$ $158.57, \mathrm{p}$ value $=\mathrm{o}=0.000]$. But the similar proportions for adults of optimal and normal blood pressure were not statistically different $[\mathrm{z}=0.40, \mathrm{p}=0.6892]$. These latter two groups were at similar risk $[\mathrm{RR}=0.93]$. But smokers of high normal blood pressure had $86 \%$ more risk compared to the risk of non-smokers [RR $=1.86]$ (Table 1 ). 


\begin{tabular}{|c|c|c|c|c|c|c|c|c|c|c|}
\hline \multirow{3}{*}{ Socioeconomic variables } & \multicolumn{8}{|c|}{ Level of blood pressure (mmHg) } & \multirow{2}{*}{\multicolumn{2}{|c|}{ Total }} \\
\hline & \multicolumn{2}{|c|}{$<120 / 80$} & \multicolumn{2}{|c|}{$<130 / 85$} & \multicolumn{2}{|c|}{$<140 / 90$} & \multicolumn{2}{|c|}{$\geq 140 / 90$} & & \\
\hline & $\mathrm{N}$ & $\%$ & $\mathrm{~N}$ & $\%$ & $\mathrm{~N}$ & $\%$ & $\mathrm{~N}$ & $\%$ & $\mathrm{~N}$ & $\%$ \\
\hline \multicolumn{11}{|l|}{ Residence } \\
\hline Rural & 180 & 43.1 & 169 & 40.4 & 40 & 9.6 & 29 & 6.9 & 418 & 43.5 \\
\hline Urban & 256 & 47.2 & 210 & 38.7 & 50 & 9.2 & 26 & 4.8 & 542 & 56.5 \\
\hline Total & 436 & 45.4 & 379 & 39.5 & 90 & 9.4 & 55 & 5.7 & 960 & 100.0 \\
\hline \multicolumn{11}{|l|}{ Religion } \\
\hline Muslim & 338 & 42.6 & 337 & 42.5 & 75 & 9.5 & 43 & 5.4 & 793 & 82.6 \\
\hline Non-Muslim & 98 & 58.7 & 42 & 25.1 & 15 & 9.0 & 12 & 7.2 & 167 & 1.4 \\
\hline \multicolumn{11}{|l|}{ Gender } \\
\hline Male & 219 & 41.3 & 227 & 42.8 & 60 & 11.3 & 24 & 4.5 & 530 & 55.2 \\
\hline Female & 217 & 50.5 & 152 & 35.3 & 30 & 7.0 & 31 & 7.2 & 430 & 44.8 \\
\hline \multicolumn{11}{|l|}{ Marital status } \\
\hline Married & 254 & 37.9 & 303 & 45.2 & 69 & 10.3 & 44 & 6.6 & 670 & 69.8 \\
\hline Single & 182 & 62.8 & 76 & 26.2 & 21 & 7.2 & 11 & 3.8 & 290 & 30.2 \\
\hline \multicolumn{11}{|l|}{ Age (years) } \\
\hline$<20$ & 22 & 78.6 & 5 & 17.9 & 1 & 3.6 & 0 & 0.0 & 28 & 2.9 \\
\hline $20-30$ & 114 & 70.4 & 34 & 21.0 & 8 & 4.9 & 6 & 3.7 & 162 & 16.9 \\
\hline $30-40$ & 142 & 56.8 & 80 & 32.0 & 18 & 7.2 & 10 & 4.7 & 250 & 26.0 \\
\hline $40-50$ & 112 & 42.4 & 119 & 45.1 & 19 & 7.2 & 14 & 5.3 & 264 & 27.5 \\
\hline $50+$ & 46 & 18.0 & 141 & 55.1 & 44 & 17.2 & 25 & 9.8 & 256 & 26.7 \\
\hline \multicolumn{11}{|l|}{ Education } \\
\hline Illiterate & 23 & 42.6 & 20 & 37.0 & 5 & 9.3 & 6 & 11.1 & 54 & 5.6 \\
\hline Primary & 57 & 49.6 & 36 & 31.3 & 11 & 9.6 & 11 & 9.6 & 115 & 12.0 \\
\hline Secondary & 100 & 43.7 & 106 & 46.3 & 15 & 6.6 & 8 & 3.5 & 229 & 23.9 \\
\hline Higher & 256 & 45.6 & 217 & 38.6 & 59 & 10.5 & 30 & 5.3 & 562 & 58.5 \\
\hline \multicolumn{11}{|l|}{ Occupation } \\
\hline Agriculture and unskilled labor & 102 & 40.0 & 120 & 47.1 & 20 & 7.8 & 13 & 5.1 & 255 & 26.6 \\
\hline Business and skilled labor & 68 & 42.2 & 70 & 43.5 & 15 & 9.3 & 8 & 5.0 & 161 & 16.8 \\
\hline Service & 115 & 54.0 & 71 & 33.3 & 20 & 9.4 & 7 & 3.3 & 213 & 22.2 \\
\hline Housewives, students and unemployed & 151 & 45.6 & 118 & 35.6 & 35 & 10.6 & 27 & 8.2 & 331 & 34.5 \\
\hline \multicolumn{11}{|l|}{ Income (000 taka) } \\
\hline$<40$ & 134 & 43.1 & 126 & 40.5 & 34 & 10.9 & 17 & 5.5 & 311 & 32.4 \\
\hline $40-60$ & 90 & 47.6 & 69 & 36.5 & 24 & 12.7 & 6 & 3.2 & 189 & 19.7 \\
\hline $60-80$ & 86 & 45.7 & 73 & 38.8 & 16 & 8.5 & 13 & 6.9 & 188 & 19.6 \\
\hline $80-100$ & 74 & 46.3 & 68 & 42.5 & 10 & 6.3 & 8 & 5.0 & 160 & 16.7 \\
\hline $100+$ & 52 & 46.4 & 43 & 38.4 & 6 & 5.4 & 11 & 9.8 & 112 & 11.6 \\
\hline \multicolumn{11}{|l|}{ Expenditure (000 taka) } \\
\hline$<30$ & 43 & 37.1 & 56 & 48.3 & 11 & 9.5 & 6 & 5.2 & 116 & 12.1 \\
\hline $30-50$ & 136 & 46.1 & 108 & 36.6 & 36 & 12.2 & 15 & 5.1 & 295 & 30.7 \\
\hline $50-70$ & 96 & 46.2 & 78 & 37.5 & 23 & 11.1 & 11 & 5.3 & 208 & 21.7 \\
\hline $70-90$ & 87 & 49.2 & 73 & 41.2 & 9 & 5.1 & 8 & 4.5 & 177 & 18.4 \\
\hline $90+$ & 74 & 45.1 & 64 & 39.0 & 11 & 6.7 & 15 & 9.1 & 164 & 17.1 \\
\hline \multicolumn{11}{|l|}{ Obesity } \\
\hline Underweight & 46 & 54.1 & 31 & 36.5 & 6 & 7.1 & 2 & 2.4 & 85 & 8.9 \\
\hline Normal & 212 & 46.5 & 182 & 39.9 & 43 & 9.4 & 19 & 4.2 & 456 & 47.5 \\
\hline Overweight & 145 & 44.3 & 131 & 40.1 & 31 & 9.5 & 20 & 6.1 & 327 & 34.1 \\
\hline Obese & 33 & 35.9 & 35 & 38.0 & 10 & 10.9 & 14 & 15.2 & 92 & 9.6 \\
\hline Utilization of time & & & & & & & & & & \\
\hline Read and use mobile phone & 105 & 75.5 & 30 & 21.6 & 3 & 2.2 & 1 & 0.7 & 139 & 14.5 \\
\hline Do household work and watch T.V. & 115 & 46.6 & 103 & 41.7 & 15 & 6.1 & 14 & 5.7 & 247 & 25.7 \\
\hline Play and use mobile phone & 151 & 62.7 & 63 & 26.1 & 21 & 8.7 & 6 & 2.4 & 241 & 25.1 \\
\hline
\end{tabular}




\begin{tabular}{|c|c|c|c|c|c|c|c|c|c|c|}
\hline Read paper and use mobile phone & 48 & 19.3 & 152 & 61.0 & 37 & 14.9 & 12 & 4.8 & 249 & 25.9 \\
\hline Watch T.V. and use mobile phone & 17 & 20.2 & 31 & 36.9 & 14 & 16.7 & 22 & 26.2 & 84 & 8.8 \\
\hline \multicolumn{11}{|l|}{ Physical work } \\
\hline Yes & 173 & 49.3 & 137 & 39.0 & 25 & 7.1 & 16 & 4.6 & 351 & 36.6 \\
\hline No & 263 & 43.2 & 242 & 39.7 & 65 & 10.7 & 39 & 7.9 & 609 & 63.4 \\
\hline \multicolumn{11}{|l|}{ Take restaurant food } \\
\hline Yes & 208 & 42.2 & 206 & 41.8 & 40 & 8.1 & 39 & 7.9 & 493 & 51.4 \\
\hline No & 228 & 48.8 & 173 & 37.0 & 50 & 10.7 & 16 & 3.4 & 467 & 48.6 \\
\hline \multicolumn{11}{|l|}{ Use can food } \\
\hline Yes & 225 & 38.5 & 253 & 43.3 & 65 & 11.1 & 41 & 7.0 & 584 & 60.8 \\
\hline No & 211 & 56.1 & 126 & 33.5 & 25 & 6.6 & 14 & 3.7 & 376 & 39.2 \\
\hline \multicolumn{11}{|l|}{ Smoking } \\
\hline Yes & 157 & 42.3 & 150 & 40.4 & 44 & 11.4 & 22 & 5.9 & 373 & 38.9 \\
\hline No & 279 & 47.4 & 229 & 38.9 & 46 & 8.1 & 33 & 5.6 & 587 & 61.1 \\
\hline \multicolumn{11}{|l|}{ Prevalence of diabetes } \\
\hline Yes & 359 & 55.9 & 224 & 34.9 & 55 & 8.6 & 4 & 0.6 & 642 & 66.9 \\
\hline No & 77 & 24.2 & 155 & 48.7 & 35 & 11.0 & 51 & 16.0 & 318 & 33.1 \\
\hline Total & 436 & 45.4 & 379 & 39.5 & 90 & 9.4 & 55 & 5.7 & 960 & 100.0 \\
\hline
\end{tabular}

Table 1: Distribution of adults according to their level of blood pressure and different socioeconomic variables.

\section{Discriminant analysis}

As per objective of the study the 4 groups of adults of 4 different levels of blood pressure were discriminated so that one or more discriminating variable(s) was/were identified as responsible factor(s) for discrimination. The variables included for the analysis were residence, religion, gender, age, marital status, education, occupation, income, expenditure, BMI, utilization of time, physical work, habit of taking restaurant food and can food, smoking habit, and prevalence of diabetes. Except residence, education and family expenditure all other variables were significantly different for 4 groups of adults. This was observed by F-test as shown here (Table 2). There were 4 groups of adults and we had 3 discriminant functions. The coefficients of different discrimination function were given in the table (Table 2). All the functions were significantly different as was observed by chi-square test derived from Wilk's [ $\Lambda=$ $0.564, \chi^{2}=542.658, \mathrm{p}$ value $\left.=0.000\right]$. Second function differed from third function $\left[\Lambda=0.863, \chi^{2}=139.562\right.$, $\mathrm{p}$ value $=0.000]$. Third function was also significant $\left[\Lambda=0.962, \chi^{2}=36.342, \mathrm{p}\right.$ value $\left.=0.000\right]$.

\begin{tabular}{|l|l|l|l|l|l|l|l|l|l|}
\hline Variable & $\begin{array}{l}\text { Wilk's } \\
\Lambda\end{array}$ & $\mathbf{F}$ & $\mathbf{p}$ value & $\begin{array}{l}\text { Coefficient } \\
\text { of } \\
\text { function 1 }\end{array}$ & $\begin{array}{l}\text { Coefficient } \\
\text { of } \\
\text { function 2 }\end{array}$ & $\begin{array}{l}\text { Coefficient } \\
\text { of } \\
\text { function 3 }\end{array}$ & $\mathbf{r}$ 1 & r2 & r3 \\
\hline Residence & 0.997 & 0.998 & 0.393 & -0.083 & -0.039 & 0.011 & -0.068 & $-0.071^{*}$ & -0.012 \\
\hline Religion & 0.980 & 6.518 & 0.000 & -0.059 & 0.103 & 0.392 & -0.131 & 0.185 & $0.436^{*}$ \\
\hline Gender & 0.983 & 5.354 & 0.001 & 0.808 & 0.796 & 0.022 & -0.103 & $0.311^{*}$ & 0.028 \\
\hline Age & 0.720 & 124.2 & 0.000 & 0.744 & -0.564 & 0.233 & $0.827^{*}$ & -0.494 & 0.061 \\
\hline Marital status & 0.947 & 17.83 & 0.000 & 0.052 & 0.150 & 0.304 & -0.304 & 0.096 & $0.395^{*}$ \\
\hline Education & 0.996 & 1.414 & 0.237 & -0.003 & -0.057 & 0.131 & -0.015 & $-0.194^{*}$ & -0.012 \\
\hline Occupation & 0.998 & 3.738 & 0.011 & 0.016 & -0.086 & 0.761 & -0.039 & 0.135 & $0.476^{*}$ \\
\hline Income & 0.998 & 2.629 & 0.049 & 0.273 & -0.250 & -2.355 & -0.004 & 0.227 & $-0.243^{*}$ \\
\hline Expenditure & 0.993 & 2.301 & 0.076 & -0.265 & 0.317 & 2.012 & -0.003 & $0.230^{*}$ & -0.169 \\
\hline BMI & 0.977 & 7.417 & 0.000 & 0.073 & 0.148 & 0.253 & 0.142 & $0.301^{*}$ & 0.241 \\
\hline $\begin{array}{l}\text { Utilization of } \\
\text { time }\end{array}$ & 0.820 & 70.10 & 0.000 & 0.262 & 0.078 & -0.075 & $0.642^{*}$ & 0.059 & -0.184 \\
\hline $\begin{array}{l}\text { Use restaurant } \\
\text { food }\end{array}$ & 0.986 & 4.527 & 0.004 & 0.002 & -0.232 & 0.112 & -0.104 & $-0.244^{*}$ & 0.207 \\
\hline Use can food & 0.968 & 10.54 & 0.000 & -0.777 & -0.758 & -0.102 & $-0.249^{*}$ & 0.042 & -0.003 \\
\hline Physical work & 0.994 & 1.986 & 0.114 & 0.088 & -0.068 & 0.166 & -0.098 & 0.005 & $-0.175^{*}$ \\
\hline
\end{tabular}




\begin{tabular}{|l|l|l|l|l|l|l|l|l|l|} 
Smoking habit & 0.996 & 1.391 & 0.244 & -0.085 & 0.000 & -0.221 & -0.074 & -0.080 & $-0.136^{*}$ \\
\hline $\begin{array}{l}\text { Prevalence of } \\
\text { diabetes }\end{array}$ & 0.847 & 57.57 & 0.000 & 0.198 & 0.599 & -0.037 & 0.517 & $0.581^{*}$ & -0.071 \\
\hline
\end{tabular}

Table 2: Results of discriminant analysis. *Largest absolute correlation coefficient between each variable and any discriminant function.

The correlation coefficients $\left(\mathrm{r}_{\mathrm{i}}, \mathrm{I}=1,2,3\right)$ of each discriminating variable and discriminant score of $\mathrm{i}$ - th variable was found out. The largest absolute value of correlation coefficient indicated the most responsible variable for discrimination. The first function discriminated well among the groups and most responsible variable for this discrimination was age followed by utilization of time and habit of taking can food. Second function discriminated well in the groups and most responsible variable for this discrimination was prevalence of diabetes followed by gender variation and BMI and habit of taking restaurant food. Third function discriminate well among the groups and the most responsible variable for this discrimination was occupation followed by religion and marital status. Beside these variables some other variables were also important for discrimination. These were identified by the largest values of correlation coefficients.

\section{Discussion}

Elevated blood pressure or hypertension is a serious health hazard leading to cardiovascular diseases and even to death worldwide $[4,24,25]$. It prevails largely in adults of 18 years and above irrespective of sex variation and it is measured by the level of blood pressure. There are different guidelines for the measurement of hypertension [6, 20,26]. In some studies, hypertensive adults were identified if their blood pressure $\geq 140 / 90 \mathrm{mmHg}$. Blood pressure below this level but $\geq 130 / 80 \mathrm{mmHg}$ was identified as pre-hypertensive state or high normal state [20]. Whatever be the measuring level of hypertension, the social determinants of it were investigated. But the adults can be classified into 4 classes according to level of blood pressure [20]. Therefore, social determinants of hypertension should not only be the target of the study. If possible, social determinants of optimal and normal blood pressure should also be the target of the study.

The present study was an attempt to do so. For this, 960 adults of ages 18 years and above residing in both urban and rural localities of Bangladesh. The percentages of optimal, normal, high normal and hypertensive adults were 45.4, 39.5, 9.4, and 5.7, respectively. Cross-classification of adults according to different socio-demographic characteristics and level of blood pressure was done to study the association between level of blood pressure and level of sociodemographic characteristics. Discriminant analysis was done to discriminate the 4 groups of adults. The analysis identified the variables age, utilization of time, use of can food, smoking habit, religion, education as the most responsible characteristics in discriminating different groups of adults.

The study indicated that urban adults were at higher risk of higher blood pressure. The risk was almost similar for normal adults compared to optimal group. Previously, similar finding for urban hypertensive adults was noted [14, 17]. Male and female adults were almost at similar risk of higher blood pressure. But compared to normal female adults, optimal female adults had lower risk of the problem. Muslim and non-Muslim adults were at similar risk of the problem. But optimality of blood pressure of female was 1.40 times likely to develop as in female subjects of normal blood pressure. Marital status was significantly associated with level of blood pressure and married adults had higher risk of facing the problem of higher blood pressure. This was not true for single adults of optimal blood pressure. The observed findings were in favour of the facts that older adults were hypertensive [5, 14, 17, 25]. This fact was evident from this study also. Higher blood pressure was almost 2.1 times likely to develop in adults of older ages as in others. But this was not true for older adults of optimal blood pressure compared to adults of normal blood pressure. Level of education was not significantly associated with higher blood pressure. But illiterate adults had higher risk of facing the problem. Again, illiterate adults of optimal and normal blood pressure had similar risk. Usually, housewives, students and unemployed adults are not directly involved in physical labour and they are exposed more to many noncommunicable diseases $[14,27,28]$. 
Similar finding was observed in this analysis also and physically inactive adults were $42 \%$ more exposed to the problem of higher blood pressure. But it was not true for group of adults of optimal and normal blood pressure. In a separate question related to direct involvement of physical labour, it was noted that higher blood pressure was 1.46 times likely to develop in physically inactive adults and 2.67 times likely in adults involved in sedentary activities as in others. But physical inactivity was not the problem for adults of optimal and normal blood pressure. Similarly, sedentary activity was not problem for these two groups of adults.

Family income and family expenditure were not significantly associated with level of blood pressure. Adults belonging to lower income group and higher expenditure group of families had slightly higher risk of facing the problem of higher blood pressure. These groups of adults were similarly exposed to optimal and normal blood pressure.

Lack of physical activity, high intake of sodium and fatty food, smoking habit, consumption of excessive alcohol and involvement in sedentary activity are examples of unhealthy lifestyle and it is the cause of many non-communicable diseases [29-31]. From the present analysis it was observed that $51.4 \%$ adults were habituated in taking restaurant food and this group had slightly more risk of high blood pressure. A big group (60.8\%) of adults were accustomed with can food and this character was 1.75 times likely to develop higher blood pressure among them as in others. The percentage of can food users was 60.8 and they had more risk of facing the problem of higher blood pressure. But use of can food was not the risk factor for adults of optimal and normal blood pressure. Smoking habit also was not the risk factor for these two groups of adults. But higher blood pressure was 1.31 times likely to prevail in smokers as in others.

Level of obesity was significantly associated with level of blood pressure and obese adults had $87 \%$ more risk of facing the problem of higher blood pressure. Obese adults of optimal blood pressure and normal blood pressure were not significantly different. Prevalence of diabetes was significantly associated with level of blood pressure.

\section{Conclusion}

The results presented above were observed in analysing data collected from 960 adults of 18 years and above residing in both urban and rural areas of Bangladesh. The data were collected by some doctors and nurses through pre-designed and pre-tested questionnaire. Adults were selected by quota sampling plan to cover around $70 \%$ diabetic patients to ensure good amount of heart, kidney, and retinopathy patients in addition to diabetes [19]. During data collection both diastolic and systolic blood pressure $(\mathrm{mmHg})$ of each of the patients was noted. Investigated adults were classified into 4 groups according to their blood pressure (BP) levels [20]. These 4 groups were: optimal (BP $\leq 120 / 80$ ), normal (BP $\leq 130 / 85$ ), high normal (BP $\leq 140 / 90$ ) and hypertensive (BP $\geq 140 / 90)$. The percentages of these 4 groups of respondents were 45.4, 39.5, 9.4, and 5.7, respectively. Association between each of different socioeconomic variables and level of blood pressure was examined and RR for higher blood pressure for a particular level of socioeconomic variable was calculated. Finally, some responsible variables were identified in discriminating the 4 groups of adults.

In the sample, $43.5 \%$ were rural adults, $17.4 \%$ were non-Muslim adults and $55.2 \%$ were male adults. These 3 groups of adults were at slightly more risk of prevalence of higher blood pressure. Percentages of respondents of ages 40 years and above, illiterate, physically inactive were 54.2, 34.5 and 5.6, respectively. Higher blood pressure was more likely in them as in others of these 3 social characteristics. Family income and expenditure were not the influencing factors for higher blood pressure. Percentage of obese subjects was 9.6. Those who were involved in sedentary activity, their percentage was 34.7. More risk of higher blood pressure was noted among these 2 groups of adults. Lifestyle factors, like habit of taking can food, smoking habit and physical inactivity enhanced the prevalence of higher blood pressure. The percentages of these three groups of adults were 60.8, 38.9, and 63.4, respectively.

From the results of association of blood pressure level and any one of socioeconomic variables and from the results of discriminant analysis it was noted that older people, married persons, persons involved in sedentary activity, physically inactive adults were at higher risk of higher blood pressure. 
The above analysis indicated that elevated blood pressure or hypertension were enhanced by some socio-demographic factors, specially age and change in lifestyle. Lifestyle and socioeconomic movement are in the same upward direction resulting upward trend in enhancing non-communicable diseases and ultimately increasing trend of pre-mature death. Upward movement of socio-demographic factors and some of its adverse impacts cannot be avoided but prevalence of adverse impacts can be reduced if people can be alerted. It needs motivation so that people can avoid sedentary lifestyle and can develop self-care management towards healthy lifestyle. The motivation can be done if some rules and regulations are formulated for healthy life which people can adopt without any extra social and economic burden. The following steps can lead to healthy life of everyone, especially of adults:

- There should be some blood screening camp in different urban and rural localities where people can join easily at least in a quarter.

- People can be motivated to avoid restaurant food and junk food and can be encouraged to take home made food as far as possible.

- People are to be encouraged to take more fruits and vegetables and fewer foods enriched in salt, sugar and saturated fat.

- People should take more pure drinking water instead of sugary drinks.

- People should be advised to limit viewing television and use of smart phone.

- Everybody should do some sorts of physical work outside their office/business hours.

- Rural and urban people should develop a habit of walking whenever it is possible.

- Urban and rural health workers and social workers can do a lot to motivate the people to follow the above steps.

\section{References}

1. Erem C, Hacihasanoglu A, Kocak M, et al. Prevalence of pre-hypertension and hypertension and associated risk factors among Turkish adults: Trabzon hypertension study. J Public Health(Oxf). 2009;31(1):47-58.

2. Ahmed A, Rahaman M, Hasan R, et al. Hypertension and associated risk factors in some selected rural areas of Bangladesh. Int J Res Med Sci. 2014;2(3):925-31.

3. Branda BS. Medical News Today. 2019.

4. World Health Organization. Hypertension: World Health Organization. Financial Report. 2019.

5. Singh S, Shankar R, Singh GP. Prevalence and associated risk factors of hypertension: A cross-sectional study in urban Varanasi. Int J Hypertens. 2017;2017(5491838):1-10.

6. Chobanian AV, Bakris GL, Black HR, et al. Seventh report of the joint national committee on prevention, detection, evaluation, and treatment of high blood pressure. Hypertension. 2003;42(6):1206-252.

7. Keamy PM, Whelton M, Reynolds K, et al. Worldwide prevalence of hypertension: a systematic review. J Hypertens. 2004;22(1):11-19.

8. Mendis S. Global status report on noncommunicable diseases 2010. Tech Rep WHO. 2010.

9. Tabrizi JS, Sadeghi-Bazargani H, Farahbakhsh M, et al. Prevalence and associated factors of prehypertension and hypertension in Iranian population: The lifestyle promotion project (LPP). PLoS One. 2016;11(10):e0165264.

10. Vasan RS, Beiser A, Seshadri S, et al. Residual lifetime risk for developing hypertension in middle-aged women and men: The Framingham Heart Study. JAMA. 2002;287(8):1003-10. 
11. Kishore J, Gupta N, Kohli C, et al. Prevalence of hypertension and determination of its risk factors in rural Delhi. Int J Hypertens. 2016;2016(7962595):1-6.

12. Everett B, Zajacova A. Gender differences in hypertension and hypertension awareness among young adults. Biodemography Soc Biol. 2015;61(1):1-17.

13. Gupta R, Gupta S. Hypertension in India: Trends in prevalence, awareness, treatment and control. RUSH J Health Sci. 2017;2(1):40-46.

14. Islam JY, Zaman MM, Haq SA, et al. Epidemiology of hypertension among Bangladeshi adults using the 2017 ACC/AHA hypertension clinical practice guidelines and joint national committee 7 Guidelines. J Hum Hypertens. 2018;32(10):668-80.

15. Rahman M, Zaman MM, Islam JY, et al. Prevalence, treatment, patterns, and risk factors of hypertension and pre-hypertension among Bangladeshi adults. J Hum Hypertens. 2018;32(5):334-48.

16. Peltzer K, Pengpid S. The prevalence and social determinants of hypertension among adults in Indonesia: A cross-sectional population-based national survey. Int J Hypertens. 2018;2018(5610725):1-9.

17. Agyemang C. Rural and urban difference in blood pressure and hypertension in Ghana, West Africa. Public Health. 2006;120(6):525-33.

18. Claas SA, Arnett DK. The role of healthy lifestyle in the primordial prevention of cardiovascular disease. Curr Cardiol Rep. 2016;18(6):56.

19. Fardus J, Bhuyan KC. Discriminating diabetic patients of some rural and urban areas of Bangladesh: A discriminant analysis approach. Euromed Bio J. 2016;11(9):134-40.

20. Staessen JA, Li Y, Hara A, et al. Blood pressure measurement anno 2016. Amer J Hypertens. 2017;30(5):45363.

21. McLachlan GJ. Discriminant analysis and statistical pattern recognition. 1st ed. Wiley Interscience; 2004.

22. Garson GD. Discriminant function analysis. 2008.

23. Bhuyan KC. A note on the application of discriminant analysis in medical research. Arch Diab Obes. 2020;2(2):142-46.

24. Michael JB, Blumenthal RS. High blood pressure: Prevention, treatment, and research. John Hopkins University.

25. Hypertension Study Group. Prevalence, awareness, treatment and control of hypertension among the elderly in Bangladesh and India: a multicenter Study. Bull World Health Organ. 2001;79(6):490-500.

26. O’Brien E, Asmar R, Beilin L, et al. European society of hypertension recommendations for conventional, ambulatory and home blood pressure measurement. J Hypertens. 2003;21(5):821-48.

27. Bhuyan KC. Socioeconomic variables responsible for diabetic retinopathy among Bangladeshi adults. Biomed J Sci \& Tech Res. 2020;25(1):18829-836.

28. Landsberg L, Molitch M. Diabetes and hypertension: pathogenesis, prevention and treatment. Clin Exp Hypertens. 2004;26(7-8):621-28.

29. Cheung B, Li C. Diabetes and hypertension: Is there a common metabolic pathway? Curr Atheroscler Rep. 2012;14(2):160-66. 
30. An estimation of the economic impact of chronic non-communicable diseases in selected countries.

31. Bhuyan KC. Factors responsible for non-communicable diseases among Bangladeshi adults. Biomed J Sci \& Tech Res. 2019;20(1):22-29. 